\title{
Groundwater-abstraction induced land subsidence and groundwater regulation in the North China Plain
}

\author{
H. Guo ${ }^{1}$, L. Wang ${ }^{2}$, G. Cheng ${ }^{1}$, and Z. Zhang ${ }^{1}$ \\ ${ }^{1}$ China Institute of Geo-Environment Monitoring, Beijing, 100081, China \\ ${ }^{2}$ Beijing Geo-Environmental Monitoring Station, Beijing, 100195, China \\ Correspondence to: H. Guo (hpguo79@gmail.com)
}

Published: 12 November 2015

\begin{abstract}
Land subsidence can be induced when various factors such as geological, and hydrogeological conditions and intensive groundwater abstraction combine. The development and utilization of groundwater in the North China Plain (NCP) bring great benefits, and at the same time have led to a series of environmental and geological problems accompanying groundwater-level declines and land subsidence. Subsidence occurs commonly in the NCP and analyses show that multi-layer aquifer systems with deep confined aquifers and thick compressible clay layers are the key geological and hydrogeological conditions responsible for its development in this region. Groundwater overdraft results in aquifer-system compaction, resulting in subsidence. A calibrated, transient groundwater-flow numerical model of the Beijing plain portion of the NCP was developed using MODFLOW. According to available water supply and demand in Beijing plain, several groundwater regulation scenarios were designed. These different regulation scenarios were simulated with the groundwater model, and assessed using a multi-criteria fuzzy pattern recognition model. This approach is proven to be very useful for scientific analysis of sustainable development and utilization of groundwater resources. The evaluation results show that sustainable development of groundwater resources may be achieved in Beijing plain when various measures such as control of groundwater abstraction and increase of artificial recharge combine favourably.
\end{abstract}

\section{Introduction}

Land subsidence can be defined as the sinking of the ground surface with respect to surrounding terrain or sea level. Land subsidence is the result of consolidation of subsurface strata caused by natural causes such as tectonic motion or maninduced causes such as the withdrawal of groundwater, oil and gas (Abidin et al., 2013; Zeitoun and Wakshal, 2013; Galgaro et al., 2014; Papadaki, 2014). Due to increased groundwater abstractions to supply rapid industrial and urban development, subsidence is prevalent in the NCP (Fig. 1), and critically impacts sustainable economic and social development. The first occurrence of land subsidence in the NCP took place in Tianjin in the 1920s, and by the 1960s it became a severe hazard in this city. Since the 1980s, the land affected by subsidence extended from cities to rural areas. Ground cracks or fissures are observed in areas where large differential subsidence occurs. Commonly subsidence in the
NCP is slow, accumulative, and irreversible. Economic losses due to subsidence in the NCP have exceeded Yuan 200 billion (Ye and He, 2006). Due to groundwater overexploitation, the maximum subsidence reached up to $1.1 \mathrm{~m}$ in Beijing plain during the period 1955-2007 (Zhang et al., 2014). To control subsidence in the Beijing plain, reducing groundwater abstraction and increasing artificial recharge will be important goals for groundwater resources management.

This paper presents a brief summary of the subsidence mechanism in the NCP. A transient 3-D groundwater flow model of the Beijing plain is used to simulate 10 proposed future groundwater regulation scenarios. A multi-criteria fuzzy pattern recognition method is used to evaluate the simulated scenarios based on a set of specified groundwater management goals and constraints. Evaluation of the proposed regulation scenarios is discussed and one scenario is recommended. 


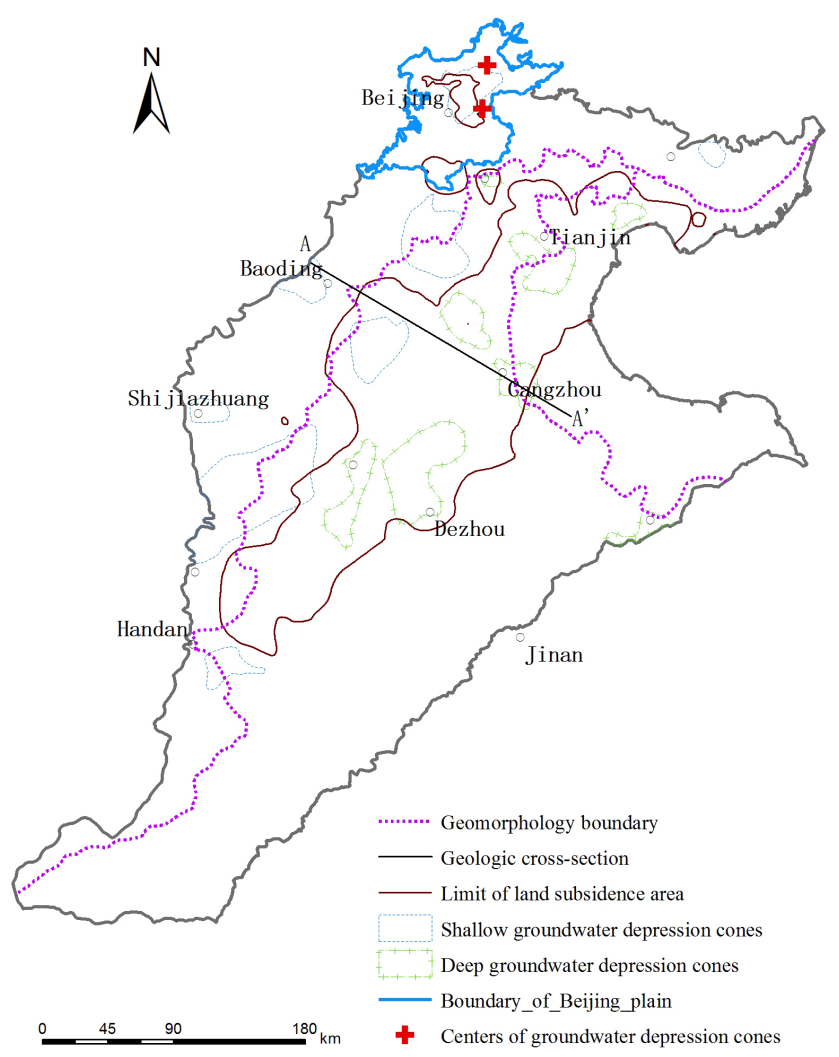

Figure 1. Distribution of the depression cones of shallow and deep groundwater, and major land subsidence area in the NCP.

\section{Regional hydrogeology}

The NCP is located in the eastern part of China, has a total area of about $140000 \mathrm{~km}^{2}$. This region comprises the plain area of Beijing, Tianjin and Hebei Province and the plain area of Henan and Shandong provinces to the north of the Yellow River, which is a typical plain landscape with elevation less than $100 \mathrm{~m}$ a.s.l. The NCP comprises three distinct hydrogeological settings within the Quaternary sediments (Fig. 1): the piedmont plain and associated major alluvial fans, the alluvial plains with many abandoned river channels, and the coastal plain strip around the margin of the Bohai Sea (Foster et al., 2004). The main stratigraphy of this region consists of unconsolidated Quaternary sediments with thickness ranging from $200 \mathrm{~m}$ to more than $600 \mathrm{~m}$, comprising unconsolidated pebble, gravel, sand, silt, and clay. Groundwater occurs principally in the pores of the unconsolidated Quaternary sediments. From the piedmont plain to alluvial and coastal plains in the middle-east portion of the NCP, the aquifer systems typically transistion from a single aquifer of sandy gravel to multiple aquifers of sand separated by silt or clay layers (Fig. 2).

\section{Influencing factors of land subsidence}

The factors affecting subsidence in the NCP are complex. Geologically, the aquifer system comprises aquifers and aquitards in the multi-layered Quaternary sediments, consisting of layers of principally coarse-grained materials, mainly unconsolidated sands, as well as layers of principally finegrained deposits, which are predominantly clays and silts that have medium to high compressibility. The alternating sequences of sand and compressible clay layers are very susceptible to deformation due to increases in effective stress accompanying groundwater-level declines. Excessive withdrawal of underground fluids such as groundwater, oil, and gas is the important driving condition for subsidence. Shallow groundwater abstraction may be the main driving condition for subsidence in the piedmont area and associated alluvial fans (e.g. Beijing and Handan). Figure 1 shows that most serious subsidence areas in the NCP lie in the alluvial plain and in the coastal strip around the margin of the Bohai Bay, which are well correlated with the distribution of depression cones of deep groundwater. In the alluvial and coastal plains, subsidence is commonly caused by withdrawal of deep groundwater, but in a few areas where large volumes of shallow groundwater, and oil and gas are extracted, subsidence is also observed.

\section{Groundwater regulation in Beijing plain}

A transient, calibrated regional groundwater flow model was developed using MODFLOW for a simulation period of 1995-2011. The model consists of 9 model layers: 5 aquifers separated by 4 aquitards. The top aquifer is unconfined and the underlying four aquifers are semi-confined.

\subsection{Formulation of regulation scenarios}

During the past 30 years, overexploitation of the groundwater resource has led to severe land subsidence, which seriously affects economically and socially sustainable development in Beijing municipality. Some actions such as artificial recharge and reduction of groundwater abstraction could be taken to overcome the subsidence crisis. The major regulation measures include: reduce or stop the abstraction from emergency groundwater well fields, reduce the abstraction for irrigation and from well fields in the downtown area and selfsupplied water supply wells, artificially increase groundwater recharge to aquifers in alluvial fans of rivers. Groundwater demand will increase with the growth of population. Ten groundwater regulation scenarios (Table 1) were designed based on the water demand and the capacity of water supply in Beijing plain. In scenario 1, the total groundwater abstraction of $2600 \times 10^{6} \mathrm{~m}^{3} \mathrm{a}^{-1}$ would remain unchanged as before. The groundwater flow model described above was used to simulate effects of proposed regulation scenarios. The sce- 
Table 1. Groundwater regulation scenarios $\left(10^{6} \mathrm{~m}^{3} \mathrm{a}^{-1}\right)$.

\begin{tabular}{lcccccccccc}
\hline Abstraction and recharge & Case 1 & Case 2 & Case 3 & Case 4 & Case 5 & Case 6 & Case 7 & Case 8 & Case 9 & Case 10 \\
\hline Domestic and industrial & 847 & 508 & 847 & 508 & 847 & 847 & 508 & 847 & 847 & 847 \\
Agriculture & 1023 & 1023 & 1023 & 1023 & 1023 & 1023 & 818 & 1023 & 1023 & 1023 \\
Well fields & 354 & 354 & 354 & 501 & 364 & 331 & 354 & 402 & 354 & 354 \\
Emergency water source & 291 & & 291 & & & 204 & & & 291 \\
Self-water supply wells & 113 & 113 & 113 & & & & 113 & 113 \\
Artificial recharge & & & 405 & & & 150 & & 215 & 520 \\
\hline Total abstraction & 2628 & 1999 & 2628 & 2033 & 2234 & 2415 & 1795 & 2270 & 2234 & 2628 \\
\hline
\end{tabular}

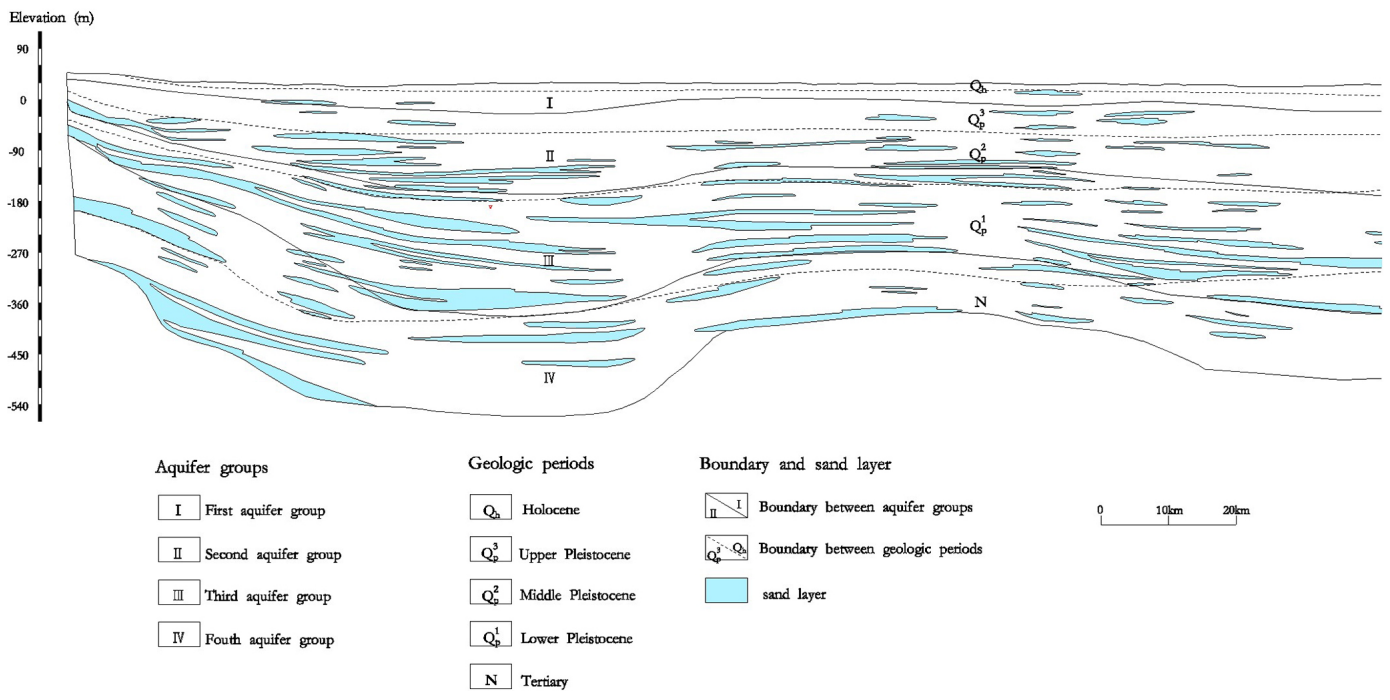

Figure 2. Hydrogeological cross section A-A' (location shown in Fig. 1).

narios were simulated for the 50 year period from 2012 to 2061.

\subsection{Multi-criteria fuzzy pattern recognition (MFPR) approach for quantitative estimation of regulation scenarios}

Assume $\boldsymbol{X}=\left(x_{1}, x_{2}, \ldots, x_{n}\right)$ be a finite set of $n$ groundwater regulation scenarios. Each regulation scenario can be valued by $m$ quantitative factors, and then the decision-making matrix can be denoted as

$\boldsymbol{X}=\left(x_{i j}\right)_{m \times n}$

where $x_{i j}$ is the value of the $i$ th quantitative factor for the $j$ th regulation scenarios.

Generally, there exist three types of estimation factors: larger-the-better, smaller-the-better and nominal-the-better by characteristics. These three types of estimation factors can, respectively, be normalized by the following equations (Chen, 2002):

$$
\begin{aligned}
& r_{i j}=\frac{x_{i j}-\min _{j} x_{i j}}{\max _{j} x_{i j}-\min _{j} x_{i j}}, i \\
& r_{i j}=\frac{\max _{j} x_{i j}-x_{i j}}{\max _{j} x_{i j}-\min _{j} x_{i j}}, i \\
& r_{i j}=1-\frac{\left|x_{i j}-x_{i}\right|}{\max _{j}\left|x_{i j}-x_{i}\right|}, i
\end{aligned}
$$

where $r_{i j}$ is the relative membership degree of the $j$ th scenario regarding the $i$ th factor, $\max _{j} x_{i j}$ and $\min _{j} x_{i j}$ are the maximum and minimum value regarding the $i$ th factor, respectively; and $x_{i}$ is the optimum target value of the $i$ th factor.

Each groundwater regulation scenario can be evaluated by $c$ levels, where the relative membership degree of the "superior" level is assigned to be 1 and relative membership degree of "inferior" level is 0 . With $c=2$, the relative membership matrix of each groundwater regulation scenario belonging to each level can be established (Chen, 2002): 


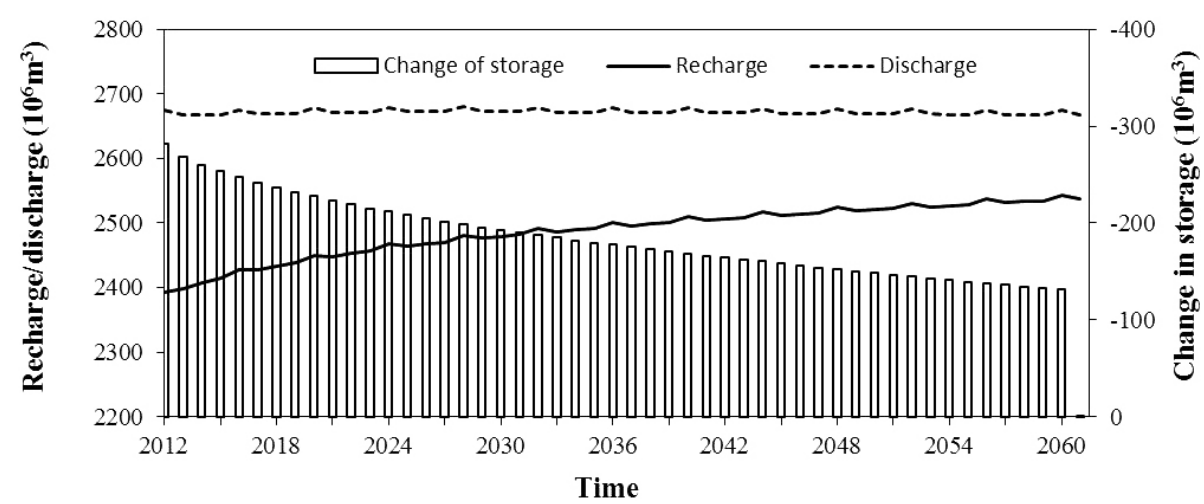

Figure 3. Change of groundwater balance under scenario 1 .

$u_{h j}=\left(\sum_{k=1}^{2} \frac{\sum_{i=1}^{m}\left[\boldsymbol{w}_{i}\left(r_{i j}-s_{i h}\right)\right]^{2}}{\sum_{i=1}^{m}\left[\boldsymbol{w}_{i}\left(r_{i j}-s_{i k}\right)\right]^{2}}\right)^{-1}$

where $u_{h j}$ is the relative membership grade of the $j$ th scenario belonging to the $h$ th ranking, $j=1,2, \ldots, n ; h=1-2$; and $\boldsymbol{w}_{i}$ is the weight vector of factor set.

The ranking feature of each groundwater regulation scenario is,

$\boldsymbol{H}=(1,2, \ldots, c) \cdot\left(u_{h j}\right)=\left(H_{1}, H_{2}, \ldots, H_{n}\right)$

where $H_{j}$ is ranking feature value of the $j$ th scenario. Ranking feature values for the groundwater development scenarios are ordered lowest to highest representing best to worst, respectively.

\section{Quantitative estimation of regulation scenarios}

Seven main factors are chosen to quantatively estimate different groundwater regulation scenarios, which include amount of groundwater exploitation, evaporation from unconfined aquifer, groundwater outflows to rivers, regional average groundwater-level depth below the ground, drawdowns in depression cone centers and the ratio of groundwater storage to total recharge. The amount of groundwater exploitation needed to meet the requirements for everyday life, city construction, agriculture and industry, and sustain groundwater levels above critical thresholds should be balanced so that severe land subsidence cannot be induced. Regional average groundwater levels should be controlled in a reasonable range so that the ecosystems dependent on groundwater can be sustained and nurtured. Sufficient groundwater discharge to rivers is required to sustain baseflow for riverine ecosystems. Evaporation from unconfined aquier is unproductive and should be reduced as much as possible. The ratio of groundwater storage to total recharge ought to keep in a reasonable range.
The ranking feature value vector for the 10 regulation scenarios $(1: 10)$ subject to the set of criteria described above was obtained from Eq. (6):

$$
\begin{aligned}
& \boldsymbol{H}=\left(\begin{array}{lllllll}
1.906 & 1.174 & 1.140 & 1.174 & 1.187 & 1.137 & 1.140
\end{array}\right. \\
& 1.1991 .1281 .119) \text {. }
\end{aligned}
$$

Scenarios 9 and 10 clearly have the lowest ranking feature values and are therefore considered as the best choices for managing the groundwater resource in the Beijing plain. Scenario 1 has the highest ranking feature value representing the worst choice for managing the groundwater resource. From a water balance perspective, the groundwater system in all scenarios approach a new equilibrium at the end of the 50 year simulation period, except scenario 1 where groundwater levels continue to decline significantly (Fig. 3), indicating poor near-future sustainability of the groundwater resources. The simulation results indicate that two major groundwater depression cones are developed, which are located in the southeast of Beijing city (Fig. 1).

In scenario 9, production from emergency well fields in the plain and most deep self-supply wells would be stopped, and reclaimed wastewater and imported surface water would be artificially recharged to aquifers in alluvial fans of major rivers. The annual total artificial recharge reaches $215 \times 10^{6} \mathrm{~m}^{3} \mathrm{a}^{-1}$ (Table 1). The total reduction of annual abstraction rates amounts to $394 \times 10^{6} \mathrm{~m}^{3} \mathrm{a}^{-1}$ compared with scenario 1 . Implementing scenario 9 would result in immediate, rapid recovery of groundwater levels, especially at the depression cone centers. As a result, the continuous decline in groundwater levels and subsidence would be greatly mitigated. Figure 4 shows the change of groundwater balance under scenario 9. Here, groundwater recharge exceeds abstraction, and groundwater storage is gradually increasing as the change in groundwater flowing out of storage is decreasing. Sustainable groundwater resources development may be achieved after many decades under this scenario.

In scenario 10, sustainable groundwater resources development may be achieved sooner. However, in the Bejing plain with limited water supply, it would be difficult to ensure 


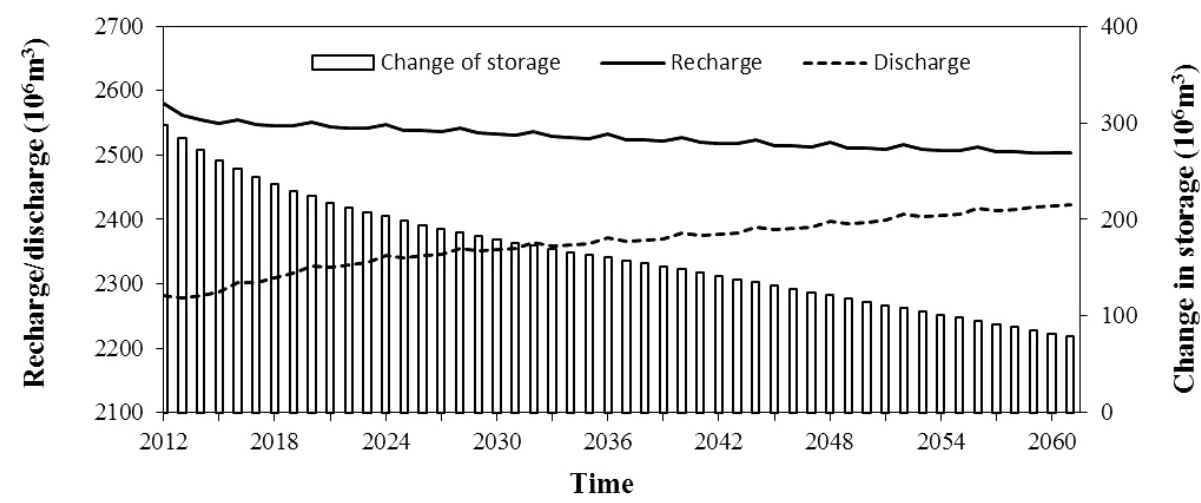

Figure 4. Change of groundwater balance under scenario 9.

an alternative water source of $520 \times 10^{6} \mathrm{~m}^{3} \mathrm{a}^{-1}$ for artificial recharge specified in this scenario. In scenario 9 , one of the best evaluated scenarios, a reasonable combination of artificial recharge and reduced abstraction would be implemented, which is more feasible and easier to implement. Thus, scenario 9 may be the best groundwater regulation scenario for the Beijing plain.

\section{Summary and conclusions}

The main factors leading to land subsidence in the NCP are represented by geological conditions such as the presence of highly compressible, thick, unconsolidated sediments and dynamic conditions of the groundwater system, e.g. groundwater abstraction. The best method to control subsidence is to recover groundwater levels especially in the known subsidence areas. Beijing is facing challenges in managing scarce water resources and controling subsidence. A multicriteria fuzzy pattern recognition (MFPR) approach is introduced and applied to quantitatively evaluate 10 proposed groundwater regulation scenarios simulated using a regional groundwater flow model for the Beijing plain. The evaluation model will be helpful for determining the most reasonable and feasible scenarios for sustainable development and utilization of groundwater resources.

Currently, in the NCP The areal extent and accumulative magnitude of subsidence is increasing though some controlling measures have been taken. Subsidence in the NCP has a direct relationship with groundwater exploitation, so rationally reducing and controlling groundwater abstraction should be carried out to decrease groundwater production. However, because both population and economic activities are heavily dependent upon the groundwater resource, it is important to seek a balance between controlling subsidence and ensuring adequate water supply so that the NCP can be developed in a sustainable and harmonious manner.
Acknowledgements. This work was supported by the China Geological Survey (No. 12120113011700), and the National Basic Research Program of China (973 Program, 2010CB428806).

\section{References}

Abidin, H. Z., Gumilar, I., Andreas, H., Murdohardono, D., and Fukuda, Y.: On causes and impacts of land subsidence in Bandung Basin, Indonesia, Environ. Earth Sci., 68, 1545-1553, 2013.

Chen, S. Y.: Optimal Fuzzy Recognition Theory and Application in Complex Water Resources System, JiLin University Press, Jilin, China, 2002.

Foster, S., Garduno, H., Evant, R., Olson, D., Tian, Y., Zhang, W., and Han, Z.: Quaternary Aquifer of the North China Plain - assessing and achieving groundwater resource sustainability, Hydrogeol. J., 12, 81-93, 2004.

Galgaro, A., Boaga, J., and Rocca, M.: HVSR technique as tool for thermal-basin characterization: a field example in N-E Italy, Environ. Earth Sci., 71, 4433-4446, 2014.

Papadaki, E. S.: Monitoring subsidence at Messara basin using radar interferometry, Environ. Earth Sci., 72, 1965-1977, 2014.

Ye, X. B. and He, Q. C.: Estimation of economic loss due to land subsidence in the North China Plain, China Land Press, Beijing, 2006.

Zeitoun, D. G. and Wakshal, E.: Land Subsidence Analysis in Urban Areas: the Bangkok Metropolitan Area Case Study, Springer Environmental Science and Engineering, Springer, Dordrecht, 2013.

Zhang, Y. Q., Gong, H. L., Gu, Z. Q., Wang, R., Li, X. J., and Zhao, W. J.: Characterization of land subsidence induced by groundwater withdrawals in the plain of Beijing city, China, Hydrogeol. J., 22, 397-409, 2014. 